\title{
Genetic Diversity, Virulence, and Meloidogyne incognita Interactions of Fusarium oxysporum Isolates Causing Cotton Wilt in Georgia
}

Alois A. Bell, Southern Plains Agricultural Research Center, United States Department of Agriculture-Agricultural Research Service (USDAARS), College Station, TX 77845; Robert C. Kemerait, Department of Plant Pathology, University of Georgia, Tifton 31793; Carlos S. Ortiz and Sandria Prom, Department of Plant Pathology and Microbiology, Texas A\&M University, College Station 77845; Jose Quintana, Southern Plains Agricultural Research Center, USDA-ARS, College Station; Robert L. Nichols, Cotton Incorporated, Cary, NC 27513; and Jinggao Liu, Southern Plains Agricultural Research Center, USDA-ARS, College Station

\begin{abstract}
Locally severe outbreaks of Fusarium wilt of cotton (Gossypium spp.) in South Georgia raised concerns about the genotypes of the causal pathogen, Fusarium oxysporum $\mathrm{f}$. sp. vasinfectum. Vegetative complementation tests and DNA sequence analysis were used to determine genetic diversity among $492 F$. oxysporum f. sp. vasinfectum isolates obtained from 107 wilted plants collected from seven fields in five counties. Eight vegetative complementation groups (VCG) were found, with VCG 01117B and VCG 01121 occurring in $66 \%$ of the infected plants. The newly recognized VCG 01121 was the major VCG in Berrien County, the center of the outbreaks. All eight VCG resulted in significant increases in the percentages of wilted leaves (27 to 53\%) and significant reductions in leaf weight (40 to $67 \%$ )

and shoot weight (33 to 60\%) after being stem punctured into Gossypium hirsutum 'Rowden'. They caused little or no significant reductions in shoot weight and height or increases in foliar symptoms and vascular browning in a soil-infestation assay. Soil infestation with Meloidogyne incognita race 3 (root-knot nematode) alone also failed to cause significant disease. When coinoculated with $M$. incognita race 3 , all VCG caused moderate to severe wilt. Therefore, the VCG identified in this study belong to the vascularcompetent pathotype, and should pose similar threats to cotton cultivars in the presence of the root-knot nematode. Use of nematode-resistant cultivars, therefore, is probably the best approach to control the disease in Georgia.
\end{abstract}

Fusarium wilt of cotton (Gossypium spp.) is a widespread disease in the United States and in most cotton-growing countries around the world. The fungal causal agents are members of the Fusarium oxysporum species complex, which causes vascular wilts and root rots in a broad range of plant species (Di Pietro et al. 2003; Gordon and Martyn 1997). Isolates have been subclassified into formae speciales based on their host range (Snyder and Hansen 1940). Isolates that attack cotton were designated as F. oxysporum $\mathrm{f}$. sp. vasinfectum W. C. Snyder \& H. N. Hansen. Isolates within $F$. oxysporum $\mathrm{f}$. sp. vasinfectum have been categorized into races based on virulence to several plant species and cultivars (Armstrong and Armstrong 1960). Races 1 to 8 were named based on arbitrary susceptibility scoring of inoculated plants of soybean (Glycine max), tobacco (Nicotiana tabacum), okra (Abelmoschus esculentus), lupine (Lupinus luteus) and alfalfa (Medicago sativa), as well as some Gossypium spp. and cultivars (Armstrong and Armstrong 1958; Armstrong and Armstrong 1960, 1978; Chen et al. 1985; Ibrahim 1966).

The current race designations in $F$. oxysporum $\mathrm{f}$. sp. vasinfectum generally are invalid for several reasons. In previous work, virulence of isolates was not always stable but varied among experiments (Armstrong and Armstrong 1958). Genetic purity of differential hosts was not established. Cotton cultivars are often formed by combining multiple lines to maintain some heterogeneity (Smith et al. 1999) and individual plants may express different levels of resistance or susceptibility. Susceptibility scores were arbitrary and framed to conform to a system developed for obligate parasites (Day 1960). Seed lots yielding 10 to $20 \%$ wilted plants were considered susceptible in one study

Corresponding author: J. Liu; E-mail: Jinggao.Liu@ars.usda.gov

The mention of firm names or trade products does not imply that they are endorsed or recommended by the United States Department of Agriculture (USDA) over other firms or similar products not mentioned. The USDA is an equal opportunity provider and employer.

*The $\boldsymbol{e}$-Xtra logo stands for "electronic extra" and indicates that one supplementary table is published online.

Accepted for publication 9 January 2017.

() 2017 The American Phytopathological Society
(Ebbels 1975), whereas 50\% or more wilted plants indicated susceptibility in other studies (Armstrong and Armstrong 1958; Kappelman 1983). Many of the published differential hosts are not readily available, and contemporary Gossypium spp. and cultivars were not able to differentiate genotypes of $F$. oxysporum $\mathrm{f}$. sp. vasinfectum (Davis et al. 1996; Holmes et al. 2009). Finally, no genetic basis for the resistance was established; therefore, a gene-for-gene relationship as occurs with races (Day 1960) is unlikely.

Molecular DNA technology has opened up new avenues for identifying $F$. oxysporum f. sp. vasinfectum genotypes, and multigene sequence analyses provided evidence that $\mathrm{f}$. $\mathrm{sp}$. vasinfectum is an artificial polyphyletic grouping based on pathogenicity to cotton (Assigbetse et al. 1994; Cianchetta et al. 2015; Fernandez et al. 1994; Holmes et al. 2009; Kim et al. 2005; Liu et al. 2011; Skovgaard et al. 2001). Old race designations were retained for genotypes containing race reference isolates (Cianchetta et al. 2015; Davis et al. 2006) but some genotypes, including major ones, could not be related to reference isolates. Though useful, over reliance on the sequence similarity to that of the old designated races resulted in designations of nonpathogenic isolates as named races. For example, "race 4-like" or MDS-12 isolates shared sequence similarity with authentic race 4 but were not virulent; race 3 isolates in the United States and LA112 genotype isolates from Arkansas also were not pathogenic (Bennett et al. 2013; Cianchetta et al. 2015; Holmes et al. 2009; Kim et al. 2005). Rigorous pathogenicity tests on multiple members of a genotype are needed to confirm their authenticity as $F$. oxysporum $\mathrm{f}$. sp. vasinfectum populations.

Genetic variations in $F$. oxysporum f. sp. vasinfectum have also been assessed by vegetative compatibility group (VCG) analyses, and 20 VCG have been identified, which include all the named reference race isolates (Davis et al. 1996; Fernandez et al. 1994; Katan and Di Primo 1999; Liu et al. 2011; Ortiz et al. 2016). Reference isolates of the named races and biotypes belong to VCG 0111 (race 1), 0112 (race 2), 0113 (races 3 and 5), 0114 (races 4 and 7), 0116 (race 6), 01111 and 01112 (Australian biotype), and 01119 (race 8) (Fernandez et al. 1994; Ortiz et al. 2016). VCG 0111 was a single-isolate VCG until the present study. VCG 0112, 01117, and 01119 are the most commonly occurring VCG in the United States (Bell et al. 2016; Ortiz et al. 2016).

Vegetative compatibility is governed by a number of vic loci in filamentous fungi and requires all the alleles at each locus to be the same in two compatible isolates (Leslie 1993). Therefore, compatibility 
between two isolates indicates that they are closely related genetically (Puhalla 1985). VCG analysis can provide a fine population definition of isolates but lacks information about genetic relatedness between two different VCG. Genomic information obtained from limited stretches of sequences may lack sufficient resolution to distinguish some VCG but may reveal genetic relationships among VCG. Thus, combining these two analyses can provide a powerful tool to categorize different pathogenic $F$. oxysporum f. sp. vasinfectum isolates. Within a VCG, there are variations in aggressiveness of virulence. However, specificity of pathogenicity to differential hosts and interactions with nematodes were usually uniform among members of a VCG (Bell et al. 2016; Davis et al. 1996; Liu et al. 2011; Puhalla 1985). Therefore, VCG analysis provides both genotype and pathotype information.

Though the race concept in $F$. oxysporum $\mathrm{f}$. sp. vasinfectum has been deemed invalid (Davis et al. 2006), fundamental differences in pathogenicity exists among VCG. Two pathotypes can be differentiated using root-dip, stem-puncture, and soil-infestation assays (Armstrong and Armstrong 1960; Bell et al. 2016; Liu et al. 2011). Root-dip assays detect both pathotypes. The vascular-competent pathotype was identified using a stem-puncture assay whereas the root-rot pathotype was identified by a soil-infestation assay (Bell et al. 2016). VCG 0111 (race 1); 0112 (race 2); 0116 (race 6); 01114, 01115, 01116, 01117A, 01117B, 01117C, 01118, and 01119 (race 8); and 01120 caused disease in the stem-puncture assay but not in the soil-infestation assay and, thus, belonged to the vascular-competent pathotype. VCG 0113 (races 3 and 5), 0114 (races 4 and 7), and 01111 (Australian Biotype) caused wilt of cotton plants with extensive root damage in the soil-infestation assay but were not pathogenic in the stempuncture assay; thus, they belong to the root-rot pathotype. When tested on Gossypium hirsutum (seven cultivars), G. barbadense 'Seabrook Sea Island 12B-2', G. arboreum United States Department of Agriculture (USDA) accession number A1-17, A. esculentus 'Clemson Spineless', M. sativa 'Grimm', N. tabacum 'Dixie Bright' and 'Gold Dollar', Glycine max 'Yelredo', Cucumis melo var. cantalupensis 'Magnum 45', and Lycopersicon esculentum 'Bonny Best', all vascular-competent VCG had similar host ranges and virulence to Gossypium spp. and cultivars, indicating that there is no basis in further classifying these VCG into races 1, 2, 6, and 8 (Bell et al. 2016).

As early as 1892 , Fusarium wilt was known to be aggravated by the root-knot nematode Meloidogyne incognita (Chitwood) (Atkinson 1892). Vascular-competent isolates caused severe disease in the presence of this nematode but inflicted little and sometime no discernable damage in its absence in the field (Garber et al. 1979; Jorgenson et al. 1978). Therefore, disease caused by vascular-competent VCG can be managed by breeding for resistance to nematodes (Wang and Roberts 2006). Root-rot pathotype VCG, on the other hand, do not require nematodes to cause severe disease (Davis et al. 1996; Kim et al. 2005). VCG of the root-rot pathotype were specific to Gossypium spp. and were more virulent to several Gossypium barbadense cultivars than were VCG 01117 isolates (Bell et al. 2016; Hutmacher et al. 2013; Kim et al. 2005; Ortiz et al. 2016). Root-rot isolates do not invade the shoot for several weeks after soil-infestation inoculation and then enter through the pith tissue and older xylem vessels. Invasion of leaves may not occur until plants are severely wilted. Breeding for resistance to the root-rot pathotype requires targeting the $F$. oxysporum $\mathrm{f}$. sp. vasinfectum $\mathrm{VCG}$ themselves.

Currently, Georgia is the second largest cotton-producing state in the United States. In 2011, a severe outbreak of Fusarium wilt occurred in a field in Berrien County and the disease seemed more common surrounding this county than elsewhere (Collins et al. 2013). The severe outbreaks have continued every year since 2011 and now include Berrien, Cook, Evans, Grady, Jeff Davis, Pierce, Tift, and Thomas Counties. Aggravation of the Fusarium wilt by nematodes such as the root-knot nematode is suspected (Whitaker et al. 2016). These severe outbreaks also have raised concerns about the possible presence of a root-rot pathotype such as VCG 0114 (race 4) that has been a major constraint in cotton production in California since 2001 (Bennett et al. 2013; Cianchetta et al. 2015). The present study was undertaken to determine the genetic diversity of $F$. oxysporum f. sp. vasinfectum in Georgia, including the possible presence of a root-rot pathotype, and to determine the interaction of VCG with nematodes.

\section{Materials and Methods}

Plant materials and fungal isolates. In the last full week of August 2014, hypocotyl stem sections were collected from wilted cotton plants (G. hirsutum) from seven fields in five Georgia counties where severe outbreaks of Fusarium wilt occurred (Table 1). In all, 10 to 23 wilted cotton plants were collected from each field (Table 1). Fields $1 \mathrm{~A}$ and 1B were planted with 'Deltapine (DP) 1252 B2RF' cotton; fields 2 and 5 with 'DP 1454 NR B2RF'; and fields 3A, 3B, and 4 with 'DP 1050 B2RF' (Table 1). DP 1252 B2RF and DP 1050 B2RF were rated resistant but DP 1454 NR B2RF was rated as moderately susceptible to the Fusarium wilt rot-knot nematode disease complex (Smith et al. 2015). The stem samples were shipped overnight to the Insect Control and Cotton Disease Research Unit, USDA Agricultural Research Service (ARS), College Station, TX. Upon receipt, samples were surface sterilized by immersing in $70 \%$ ethanol for $3 \mathrm{~min}$ and rinsing with sterile water. The sterilized stems were decorticated, trimmed, and immersed again in $70 \%$ ethanol for $1 \mathrm{~min}$, rinsed with sterile water, and cut into quadrants lengthwise. Each quadrant was placed on Komada's Fusarium medium (Komada 1975). After 5 days, plates were observed under a dissecting microscope for the presence of Fusarium-like colonies and sporulation. One or two of the selected quadrants from each stem sample were placed in $2 \mathrm{ml}$ of sterile water and vortexed for $10 \mathrm{~s}$. Three drops of the resulting supernatant and 10-fold dilutions were spread plated on potato dextrose agar (Difco Laboratories, Detroit) containing chloramphenicol at $100 \mathrm{ppm}$ and tetracycline at $50 \mathrm{ppm}$ (PDAA). Six individual $F$. oxysporum-like colonies, with an attempt to include

Table 1. Distribution of vegetative compatibility groups (VCG) among Fusarium oxysporum isolates obtained from infected plants in five counties of Georgia in 2014

\begin{tabular}{|c|c|c|c|c|c|c|c|c|c|}
\hline \multirow[b]{2}{*}{ County, field, and DPy } & \multirow[b]{2}{*}{$N^{\mathbf{z}}$} & \multicolumn{8}{|c|}{ Number of infected plants (number of isolates) per VCG $^{x}$} \\
\hline & & $0111(4)$ & $0112(5)$ & 01117B (1B) & $01117 \mathrm{C}(1 \mathrm{C})$ & $01118(8)$ & $01119(2)$ & $01120(10)$ & $01121(12)$ \\
\hline Evans, 3A, $1050 \mathrm{~B} 2 \mathrm{RF}$ & 10 & $0(0)$ & $2(2)$ & $8(44)$ & $1(6)$ & $0(0)$ & $0(0)$ & $0(0)$ & $3(8)$ \\
\hline Evans, 3B, $1050 \mathrm{~B} 2 \mathrm{RF}$ & 16 & $0(0)$ & $2(12)$ & $10(54)$ & $3(18)$ & $0(0)$ & $0(0)$ & $0(0)$ & $2(7)$ \\
\hline Berrien, 2, 1454 NR B2RF & 23 & $3(13)$ & $0(0)$ & $1(6)$ & $5(20)$ & $0(0)$ & $0(0)$ & $0(0)$ & $17(88)$ \\
\hline Tift, 1A, $1252 \mathrm{~B} 2 \mathrm{RF}$ & 13 & $0(0)$ & $0(0)$ & $1(6)$ & $0(0)$ & $0(0)$ & $0(0)$ & $0(0)$ & $4(15)$ \\
\hline Tift, 1B, 1252 B2RF & 15 & $0(0)$ & $0(0)$ & $5(15)$ & $0(0)$ & $0(0)$ & $0(0)$ & $0(0)$ & $5(13)$ \\
\hline Cook, 4, 1050 B2RF & 17 & $0(0)$ & $0(0)$ & $6(25)$ & $1(2)$ & $7(28)$ & $0(0)$ & $0(0)$ & $9(39)$ \\
\hline Grady, 5, 1454 NR B2RF & 13 & $0(0)$ & $0(0)$ & $6(31)$ & $0(0)$ & $1(6)$ & $1(6)$ & $5(20)$ & $2(8)$ \\
\hline Total & 107 & $3(13)$ & $4(14)$ & 37 (181) & $10(46)$ & $8(34)$ & $1(6)$ & $5(20)$ & 42 (178) \\
\hline
\end{tabular}

${ }^{\mathrm{x}}$ For VCG, the first number = international VCG code. Race 1 reference isolate ATCC 16421 belongs to VCG 0111, race 2 reference isolate ATCC 16611 to VCG 0112, and race 8 reference isolate NRRL31665 to VCG 01119. Number in parentheses = local VCG code (Insect Control and Cotton Disease Research Unit, USDA-ARS).

${ }^{y}$ Counties were arranged from northeast to southwest along the Georgia cotton belt that runs parallel to the geographic fall line. Berrien, Tift, and Cook Counties share borders among them. DP = Deltapine cultivar.

${ }^{\mathrm{z}}$ Number of infected plants analyzed. 
all the different colony morphology types from each stem section, were selected and further purified by single sporing on PDAA. Species were preliminarily identified according to Nelson et al. (1983) and subsequently confirmed by DNA sequence analyses (described below). Isolates suspected being of $F$. proliferatum, $F$. fujikuroi, and $F$. verticillioides were grown on water agar containing $0.6 \%$ $\mathrm{KCl}$ to examine them for the presence of conidial chains (Fisher et al. 1983). Cultures from single spores were grown on PDAA or sorghum seed, dried, and then stored at $30^{\circ} \mathrm{C}$.

Vegetative compatibility analysis. Vegetative compatibility of the isolates was tested according to Puhalla (1985) and Correll et al. (1987). Single-spore isolates were grown on freshly prepared potato sucrose agar (Puhalla 1985) containing $2 \%$ sodium chlorate (PSAC). Fast-growing sectors or dense circular areas within colonies were subcultured to new PSAC. After 3 to 5 days, hyphal fronts from subcultures were transferred to the nitrate medium. Nitrate-nonutilizing (nit) mutants were identified using the media of Puhalla and Spieth (1983). Complementation among nit-1, nit-3, and nit-M mutants were first tested within an isolate to confirm that it was heterokaryon selfcompatible and then among confirmed isolates to determine relationships. Relationships of the Georgia $F$. oxysporum f. sp. vasinfectum isolates to the known VCG were tested by paring nit mutants of Georgia isolates against nit- $M$ testers of the known VCG (Bell et al. 2016; Ortiz et al. 2016) and were assigned to corresponding VCG. A new VCG found in this study that failed to complement the known VCG was given the international code VCG 01121, according to Katan and Di Primo (1999), after further DNA sequence analysis and pathogenicity tests (see below). Numbers of plants infested with each VCG and numbers of isolates belonging to each VCG are enumerated (Table 1). Numbers of plants infected simultaneously by two isolates belonging to different VCG were counted and their expected frequencies, under the assumption that infection by the second isolate belonging to another VCG is independent with regard to the presence of the first isolate in the plant and the presence of other VCG in the field, were calculated (Table 2). Thus, the expected number of plants with duplex
VCG was calculated by multiplying the frequencies of the component VCG in the type and the total number of plants infected by all the identified VCG within the field given in Table 1. For example, four VCG were identified in field 2 infecting 22 plants, with VCG 1B infecting 1 plant and VCG 12 infecting 17 plants. The expected number of plants infected simultaneously with VCG $1 \mathrm{~B}$ and VCG 12 is then $1 / 22 \times$ $17 / 22 \times 22=0.8$. Out of consideration of the chance of failing to pick the two VCG present in the plant because we picked only six isolates from each plant, each of the calculated values was further adjusted by multiplying with a factor of $0.97\left(1-1 / 2^{5}\right)$. The VCG or the noncomplementing isolates that failed to cause disease in cotton (see below) were not assigned an international code, as suggested by Katan and Di Primo (1999). Many of these VCG consisted of isolates that formed conidial chains on $\mathrm{KCl}$ plates.

DNA extraction, amplification, sequencing, and phylogenetic analysis. At least three isolates within each VCG, preferably arising from different fields or at least from different plants, were selected for DNA sequence analysis. VCG 01119 was identified from only one plant; therefore, only two isolates were selected. One isolate from each of the nonpathogenic VCG was also selected. Single-spored cultures were grown in potato dextrose broth (Difco Laboratories) at $24^{\circ} \mathrm{C}$ for 5 days without shaking. Mycelium was harvested on a sterile filter paper (Whatman, Maidstone, England) by vacuuming out the liquid and immediately flash freezing in liquid nitrogen. Fungal DNA was isolated by a modified minipreparation procedure (Woloshuk et al. 1989) and resuspended in sterile distilled water. DNA concentrations were determined via Nanodrop (Thermo Scientific, Wilmington, DE) and integrity was analyzed by gel electrophoresis.

Portions of three nuclear genes-translation elongation factor $(E F-1 \alpha)$, phosphate: $\mathrm{H}^{+}$symporter $(P H O)$, and $\beta$-tubulin $(B T)$-were amplified using primer pairs EF-1A and EF1885R, PHO48F and $\mathrm{PHO} 2034$, and $\mathrm{BT} 100 \mathrm{~F}$ and $\mathrm{BT} 1828 \mathrm{R}$, respectively (Ortiz et al. 2016). Amplification was carried out in $100-\mu 1$ reaction mixtures with $100 \mathrm{ng}$ of template DNA, $1.5 \mathrm{mM} \mathrm{MgCl} 2,200 \mu \mathrm{M}$ dNTP, $200 \mathrm{nM}$ each primer, and $2.5 \mathrm{U}$ of GoTaq DNA polymerase in $1 \times$ GoTaq

Table 2. Actual frequencies of plants infected simultaneously by isolates belonging to two different vegetative compatibility groups (VCG) and their expected frequencies ${ }^{y}$

\begin{tabular}{|c|c|c|c|c|c|c|c|c|c|c|c|c|c|c|}
\hline \multirow[b]{3}{*}{ Type $^{z}$} & \multicolumn{4}{|c|}{ Evans } & \multirow{2}{*}{\multicolumn{2}{|c|}{$\begin{array}{c}\text { Berrien } \\
\text { Field } 2\end{array}$}} & \multicolumn{4}{|c|}{ Tift } & \multirow{2}{*}{\multicolumn{2}{|c|}{$\begin{array}{c}\text { Cook } \\
\text { Field } 4\end{array}$}} & \multirow{2}{*}{\multicolumn{2}{|c|}{$\begin{array}{c}\text { Grady } \\
\text { Field } 5\end{array}$}} \\
\hline & \multicolumn{2}{|c|}{ Field 3A } & \multicolumn{2}{|c|}{ Field 3B } & & & \multicolumn{2}{|c|}{ Field 1A } & \multicolumn{2}{|c|}{ Field 1B } & & & & \\
\hline & Exp & $\overline{\text { Obs }}$ & $\overline{\operatorname{Exp}}$ & $\overline{\text { Obs }}$ & $\overline{\operatorname{Exp}}$ & $\overline{\text { Obs }}$ & $\overline{\operatorname{Exp}}$ & $\overline{\text { Obs }}$ & $\overline{\operatorname{Exp}}$ & $\overline{\text { Obs }}$ & $\overline{\operatorname{Exp}}$ & $\overline{\text { Obs }}$ & $\overline{\operatorname{Exp}}$ & $\overline{\text { Obs }}$ \\
\hline $1 \mathrm{~B}-1 \mathrm{C}$ & 0.8 & 0 & 1.8 & 0 & 0.2 & 0 & $\ldots$ & $\ldots$ & $\ldots$ & $\ldots$ & 0.3 & 0 & $\ldots$ & $\ldots$ \\
\hline 1B-10 & $\ldots$ & $\ldots$ & $\ldots$ & $\ldots$ & $\ldots$ & $\ldots$ & $\ldots$ & $\ldots$ & $\ldots$ & $\ldots$ & $\ldots$ & $\ldots$ & 2.4 & 2 \\
\hline 1B-12 & 2.3 & 2 & 1.2 & 1 & 0.7 & 0 & 0.8 & 0 & 2.7 & 1 & 3.1 & 3 & 1.0 & 1 \\
\hline $1 \mathrm{~B}-2$ & $\ldots$ & $\ldots$ & $\ldots$ & $\ldots$ & $\ldots$ & $\ldots$ & $\ldots$ & $\ldots$ & $\ldots$ & $\ldots$ & $\ldots$ & $\ldots$ & 0.5 & 0 \\
\hline $1 B-4$ & $\ldots$ & $\ldots$ & $\ldots$ & $\ldots$ & 0.1 & 0 & $\ldots$ & $\ldots$ & $\ldots$ & $\ldots$ & $\ldots$ & $\ldots$ & $\ldots$ & $\ldots$ \\
\hline $1 B-5$ & 1.6 & 2 & 1.2 & 0 & $\ldots$ & $\ldots$ & $\ldots$ & $\ldots$ & $\ldots$ & $\ldots$ & $\ldots$ & $\ldots$ & $\ldots$ & $\ldots$ \\
\hline $1 \mathrm{~B}-8$ & $\ldots$ & $\ldots$ & $\ldots$ & $\ldots$ & $\ldots$ & $\ldots$ & $\ldots$ & $\ldots$ & $\ldots$ & $\ldots$ & 2.4 & 1 & 0.5 & 0 \\
\hline $1 \mathrm{C}-12$ & 0.3 & 0 & 0.4 & 0 & 3.7 & 2 & $\ldots$ & $\ldots$ & $\ldots$ & $\ldots$ & 0.5 & 1 & $\ldots$ & $\ldots$ \\
\hline $1 \mathrm{C}-4$ & & & & & 0.7 & 0 & $\ldots$ & $\ldots$ & $\ldots$ & $\ldots$ & $\ldots$ & $\ldots$ & $\ldots$ & $\ldots$ \\
\hline $1 C-5$ & 0.2 & 0 & 0.4 & 0 & $\ldots$ & $\ldots$ & $\ldots$ & $\ldots$ & $\ldots$ & $\ldots$ & $\ldots$ & $\ldots$ & $\ldots$ & $\ldots$ \\
\hline $1 \mathrm{C}-8$ & $\ldots$ & $\ldots$ & $\ldots$ & $\ldots$ & $\ldots$ & $\ldots$ & $\ldots$ & $\ldots$ & $\ldots$ & $\ldots$ & 0.4 & 0 & $\ldots$ & $\ldots$ \\
\hline $10-12$ & $\ldots$ & $\ldots$ & $\ldots$ & $\ldots$ & $\ldots$ & $\ldots$ & $\ldots$ & $\ldots$ & $\ldots$ & $\ldots$ & $\ldots$ & $\ldots$ & 0.8 & 0 \\
\hline $10-2$ & $\ldots$ & $\ldots$ & $\ldots$ & $\ldots$ & $\ldots$ & $\ldots$ & $\ldots$ & $\ldots$ & $\ldots$ & $\ldots$ & $\ldots$ & $\ldots$ & 0.4 & 0 \\
\hline $10-8$ & $\ldots$ & $\ldots$ & $\ldots$ & $\ldots$ & $\ldots$ & $\ldots$ & $\ldots$ & $\ldots$ & $\ldots$ & $\ldots$ & $\ldots$ & $\ldots$ & 0.4 & 0 \\
\hline $12-2$ & $\ldots$ & $\ldots$ & $\ldots$ & $\ldots$ & $\ldots$ & $\ldots$ & $\ldots$ & $\ldots$ & $\ldots$ & $\ldots$ & $\ldots$ & $\ldots$ & 0.2 & 0 \\
\hline $12-4$ & $\ldots$ & $\ldots$ & $\ldots$ & $\ldots$ & 2.2 & 0 & $\ldots$ & $\ldots$ & $\ldots$ & $\ldots$ & $\ldots$ & $\ldots$ & $\ldots$ & $\ldots$ \\
\hline $12-5$ & 0.6 & 0 & 0.2 & 0 & $\ldots$ & $\ldots$ & $\ldots$ & $\ldots$ & $\ldots$ & $\ldots$ & $\ldots$ & $\ldots$ & $\ldots$ & $\ldots$ \\
\hline $12-8$ & $\ldots$ & $\ldots$ & $\ldots$ & $\ldots$ & $\ldots$ & $\ldots$ & $\ldots$ & $\ldots$ & $\ldots$ & $\ldots$ & 3.6 & 1 & 0.2 & 0 \\
\hline $2-8$ & $\ldots$ & $\ldots$ & $\ldots$ & $\ldots$ & $\ldots$ & $\ldots$ & $\ldots$ & $\ldots$ & $\ldots$ & $\ldots$ & $\ldots$ & $\ldots$ & 0.1 & 0 \\
\hline
\end{tabular}

y Counties were arranged from northeast to southwest along the Georgia cotton belt that runs parallel to the geographic fall line. Exp $=$ expected number of plants with a duplex-VCG type, calculated by multiplying the frequencies of the component VCG in the type and the total number of plants infected by all the identified VCG within the field. For example, 4 VCG were identified in field 2 infecting 22 plants, with VCG1B infecting 1 plant and VCG12 infecting 17 plants. The expected number of plants infected simultaneously with VCG1B and VCG12 is then $1 / 22 \times 17 / 22 \times 22=0.8$. Because we only picked six isolates for each plant, each of the calculated values was further adjusted by multiplying with a factor of $0.97\left(1-1 / 2^{5}\right)$. Obs $=$ the actual observed number of plants simultaneously infected with designated VCG in the given field. Values of expected number of plants with the designated duplex-VCG type exceeding 0.5 are in bold for easy view. Note that no duplex-VCG actually occurred when the value was less than 0.5 .

${ }^{\mathrm{z}}$ Local VCG code (Insect Control and Cotton Disease Research Unit, USDA-ARS) was used to indicate the duplex-VCG type that infects a plant. 
Flexi Buffer (Promega Corp., Madison, WI) and performed in an Eppendorf Mastercycler (Eppendorf, Westbury, NY) with the following program: initial denaturing at $94^{\circ} \mathrm{C}$ for $2 \mathrm{~min} ; 35$ cycles of denaturing at $94^{\circ} \mathrm{C}$ for $30 \mathrm{~s}$, annealing at $56^{\circ} \mathrm{C}$ for $30 \mathrm{~s}$, and extension at $72^{\circ} \mathrm{C}$ for $2 \mathrm{~min}$; and final extension at $72^{\circ} \mathrm{C}$ for $5 \mathrm{~min}$. An aliquot of polymerase chain reaction (PCR) products was checked for target amplicons using gel electrophoresis. Additional internal primers were used for sequencing the whole amplicons (Ortiz et al. 2016). The PCR products were sequenced through MCLAB (South San Francisco, CA) by Sanger sequencing and analyzed with a 3730XL DNA Analyzer. Sequences were edited and aligned using Sequencher (version 4.8; Gene Codes, Ann Arbor, MI). Sequences for the Fusarium isolates were deposited in GenBank with the following accession numbers: KX708524 to KX708592 for the pathogenic $F$. oxysporum isolates and KY293646 to KY293669 for the nonpathogenic $F$. fujikuroi or $F$. proliferatum isolates.

DNA sequences were aligned using the Clustal W program (Thompson et al. 1994) and adjusted manually. The phylogenetic tree was constructed using the neighbor-joining method (Saitou and Nei 1987) implemented in the phylogenetic analysis program of MEGA 6.0 (Tamura et al. 2007) based on concatenated sequences of $E F-1 \alpha$, $P H O$, and $B T$ genes of the selected isolates. Sequences of a Fusarium sp. isolate AuSeed1 (accession numbers KX844701 to KX844703, Liu et al. 2011) and F. verticillioides strain 7600 (National Center for Biotechnology Information [NCBI] genome assembly accession number GCA_000149555.1) were included to root the tree. Kimura's two-parameter distance option and pairwise deletion of gap option were used. Statistical support for the derived tree was obtained by running 1,000 bootstrap replicates.

Pathogenicity test with stem-puncture inoculations. This test was designed to detect the vascular-competent pathotype of $F$. oxysporum f. sp. vasinfectum. An assessment of overall pathogenic diversity in the collected 542 Fusarium isolates from the 107 stem sections, including the 50 conidial chain-forming isolates, was conducted by stem-puncture inoculations (Bugbee and Sappenfield 1972) of susceptible $G$. hirsutum 'Rowden'. Planting soil was prepared by mixing 18 liters of washed sand, 12 liters of vermiculite, 12 liters of dried peat moss, $1 \mathrm{~kg}$ of gypsum, $300 \mathrm{~g}$ of dolomitic lime, and $50 \mathrm{~g}$ of esmigran (Scotts-Sierra Horticultural Products Co., Marysville, OH). The mixture was placed in 500-ml cups, drilled and fitted with a fiberglass screen for drainage, and was saturated with reverse-osmosis water. After 24 to $48 \mathrm{~h}$, the mixture was pasteurized using aerated steam $\left(74^{\circ} \mathrm{C}\right)$ for $16 \mathrm{~h}$ and then fertilized with $300 \mathrm{mg}$ of Peter's Peat-Lite Special 10: 30:20 (N-P-K) containing chelated minor elements (Scotts-Sierra Horticultural Products Co.). Cotton seed were chipped near the chalaza and wrapped in germination paper saturated with water. The wrapped seed were placed in a $30^{\circ} \mathrm{C}$ incubator for $24 \mathrm{~h}$ and then transferred to a $16^{\circ} \mathrm{C}$ room for an additional $24 \mathrm{~h}$. Seedlings with a radicle length of about 2 to $3 \mathrm{~cm}$ were transplanted to the prepared $500-\mathrm{ml}$ soil cups, one plant per cup. Seedlings were grown in a growth chamber at $25^{\circ} \mathrm{C}$ for $13 \mathrm{~h}$ of light and $20^{\circ} \mathrm{C}$ for $11 \mathrm{~h}$ of darkness and fertilized weekly with $150 \mathrm{mg}$ of Peter's Peat-Lite Special 10:30:20 containing chelated minor elements until the end of the experiment.

Inocula were prepared by flooding 7-day-old PDAA cultures with sterile water, dislodging the conidia from the plates with a glass rod, and filtering the resulting conidial suspension through several layers of Kimwipes (Kimberly-Clark Inc., Roswell, GA). Conidia concentrations were determined with a hemocytometer, and the filtrates were adjusted to $2 \times 10^{7}$ conidia/ml by adding water.

When the fourth true leaf of plants became about 1 to $3 \mathrm{~cm}$ wide, a $20 \mu$ l-droplet of conidial suspension of an isolate was deposited on the surface of the hypocotyl $2 \mathrm{~cm}$ below the cotyledonary node at a site perpendicular to the cotyledons using a syringe fitted with a 23-gauge needle. The needle was punctured through the droplet into the xylem, resulting in the droplet being sucked into the stem. A second identical inoculation was made on the opposite side of the stem $1 \mathrm{~cm}$ bellow the cotyledonary node. The treatment was one plant per isolate. Isolates within each VCG served as replicates and the conidial chain-forming $F$. fujikuroi or $F$. proliferatum isolates served as nonpathogenic controls. The majority of the field-collected wilted plants were infected by isolates belonging to a single VCG. The whole collection of isolates was evaluated in separate environmental chambers on four different dates, with each evaluation containing the VCG in a randomized pattern. Therefore, each evaluation served as a trial. The evaluations and replications served as random variables in the statistical analysis. A highly pathogenic VCG 01117A isolate, American Type Culture Collection (ATCC) 46644, from California was used as a positive control with six replications (Liu et al. 2011). After 3 weeks of incubation in a growth chamber at $25^{\circ} \mathrm{C}$ for $13 \mathrm{~h}$ light and $20^{\circ} \mathrm{C}$ for $11 \mathrm{~h}$ of darkness, number of wilted leaves, total number of leaves including leaf scars, fresh leaf weight, fresh shoot weight, and shoot height were measured. Percentage of leaves wilted was calculated by (number of wilted leaves)/(number of total leaves) $\times 100$. The fourth internode was cut, immersed in $70 \%$ ethanol for 3 min, decorticated, rinsed with sterile water, and plated on PDAA. After 7 days, emergence of Fusarium spp. from sections was recorded. At least several isolates within each VCG were subjected to DNA sequence analysis to confirm recovery of inoculum.

Soil-infestation assays and interactions with nematodes. This test was designed for the detection of the root-rot $F$. oxysporum $\mathrm{f}$. sp. vasinfectum pathotype as well as $F$. oxysporum $\mathrm{f}$. sp. vasinfectumroot-knot nematode interaction. In all, 3 isolates each from VCG 0111 and VCG 0112, 13 isolates from VCG 01117B, 12 isolates from VCG 01117C, 6 isolates from VCG 01118, 5 isolates from VCG 01120, and 7 isolates from VCG 01121 were used to inoculate 'Rowden'. Isolates were named in the format of field number-plant number-isolate number. For example, the first isolate in Supplementary Table S1, designated 2-1-6, was the sixth isolate from the wilted plant number $1 \mathrm{col}-$ lected in field 2 (Berrien County). Assay soils were prepared by mixing $30 \mathrm{~kg}$ of sandy loam, $10 \mathrm{~kg}$ of washed sand, and $80 \mathrm{~g}$ of fine ground oatmeal. The mixture was pasteurized and fertilized as described above.

$F$. oxysporum f. sp. vasinfectum inocula were prepared as above, except that the final concentrations were adjusted to $5 \times 10^{6}$. A race 3 root-knot nematode culture, originally from a cotton field in Texas and provided by Dr. James Starr (Department of Plant Pathology and Microbiology, Texas A\&M University), was maintained and multiplied on 'Rutgers' tomato. Nematode eggs were prepared by extracting infested tomato roots with $0.8 \% \mathrm{NaOCl}$ for $4 \mathrm{~min}$, filtering the extract through 200-mesh sieves, collecting eggs on 500-mesh sieves, and rinsing the eggs with sterile water (Hussey and Barker 1973). Eggs were resuspended in sterile water at a concentration of 1,000 eggs $/ \mathrm{ml}$. 'Rowden' seed were germinated and transplanted into 500-ml cups filled with the assay soil, one plant per cup. F. oxysporum f. sp. vasinfectum inoculum $(1 \mathrm{ml})$ was injected into each of six locations equidistant from each other and $1 \mathrm{~cm}$ away from the radicle. Injection of $F$. oxysporum $\mathrm{f}$. sp. vasinfectum conidia was conducted with an 18-gauge needle starting from $4 \mathrm{~cm}$ deep and retracting to the soil surface while injecting conidial suspension. Five plants were treated with each isolate. Ten control plants were treated with the same volume of sterile water. The treated plants were grown in the growth chamber with the same temperature, light, and fertilization regimes as described above. One week after planting, 2 of the 5 plants treated with each isolate and 4 of the 10 control plants were inoculated with root-knot nematodes. For the treatment, $1 \mathrm{ml}$ of 1,000 eggs $/ \mathrm{ml}$ was injected into each of six locations equidistant from the plant and the edge of the cup, as well as equidistant from each other. Injection was conducted with a 14-gauge needle starting from $6 \mathrm{~cm}$ deep and retracting to the soil surface while injecting egg suspension. The needle was perforated by drilling six 0.5 -mm-diameter holes on the needle sidewall with even spacing at the $2-\mathrm{cm}$ tip end and sealing the tip. The plants were further incubated in the growth chamber for another 5 weeks and then evaluated as described above. The stem sections just above the soil line were also evaluated for vascular staining using the following vascular staining index: $0=$ no staining, $1=0$ to $10 \%$ of cross section was stained, $2=10$ to $30 \%$ of area was stained, $3=30$ to $70 \%$ of area was stained, $4=70$ to $90 \%$ of area was stained, and $5=90$ to $100 \%$ of area was stained or the plant was dead. The whole experiment was repeated twice.

Statistical analysis. The relationships between the observed duplex-VCG type frequencies and their expected frequencies were 
modeled using a linear regression approach (PROC REG, SAS version 9.4; SAS Institute Inc., Cary, NC). The former variable was treated as the outcome variable and the latter as the regressor variable. The resulting intercept and slope were tested for significant deviation from 0 and 1, respectively. A subset of data involving only the duplex-VCG type 1B-12 (plants infected simultaneously with a VCG 01117B isolate and a VCG 011121 isolate) across all studied fields was subjected to the same regression and tests. Data from response variables of the stem-puncture inoculations and soil-infestation $F$. oxysporum $\mathrm{f}$. sp. vasinfectum-nematode inoculations were separately modeled using a mixed-models approach (PROC GLIMMIX, SAS version 9.4). In the first analysis, VCG was considered as a fixed effect. Random effects included evaluation and replication nested within evaluation, with each isolate within one VCG considered as one replication. In the second analysis, we first modeled only the shoot weight response variable within each VCG plus the water controls. Fungal isolates, nematodes, and their interaction were considered as fixed effects; trials and replications nested within trials were considered as random effects. We then modeled each response variable on all of the data, with VCG, nematode, and their interaction considered as fixed effect. Random effects included trial, isolate within each VCG nested in trial, and replication nested within the isolate. For all models, Studentized marginal and conditional residuals were plotted to verify that residuals were independent and normally distributed. In the second analysis, the response variables (percent leaves wilted and vascular browning index) were transformed as their squares root to satisfy these requirements. For clarity, means of these two variables are presented in the original

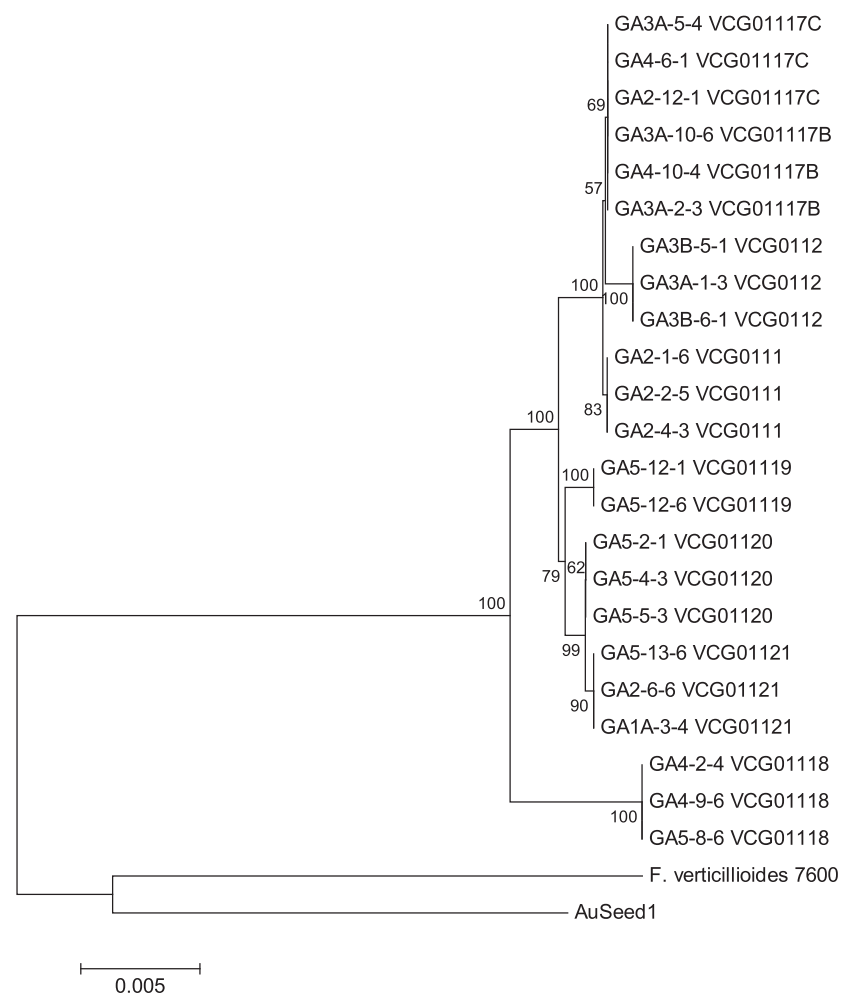

Fig. 1. Phylogenetic tree of Fusarium oxysporum isolates belonging to eight vegetative compatibility groups (VCG) from Georgia. Race 1 reference isolate ATCC 16421 belongs to VCG 0111, race 2 reference isolate ATCC 16611 to VCG 0112, and race 8 reference isolate NRRL31665 to VCG 01119 . The tree was constructed by the neighbor-joining method based on the concatenated sequences of translation elongation factor $1-\alpha\left(1,825 \mathrm{bp}\right.$ aligned length), phosphate: $\mathrm{H}^{+}$symporter $(1,944 \mathrm{bp}$ aligned length), and $\beta$-tubulin (1,885 bp aligned length). Sequences of an $F$. verticillioides isolate Fv7600 (NCBI genome accession number GCA_000149555.1) and a Fusarium sp. isolate AuSeed1 (accession numbers KX844701 to KX844703) (Liu et al. 2011) were also included to root the tree. Distances were determined by Kimura's two-parameter model. Bootstrap frequencies from 1,000 replications are noted next to the branches. The scale is equivalent to five nucleotide substitutions per $1,000 \mathrm{bp}$. untransformed metric. Means were separated at $P=0.05$ using least squares means with the Tukey-Kramer adjustment.

\section{Results}

Genetic diversity. Genetic diversity of $F$. oxysporum f. sp. vasinfectum in Georgia was determined on isolates from stem sections of 107 wilted plants collected from seven fields located in five counties along the cotton belt that runs parallel to the geographic fall line (Table 1). Six individual $F$. oxysporum-like isolates were obtained from each plant in such a way as to represent all the different 48-h-old colony morphology types present within the plant. The majority of the isolates $(n=492)$ belonged to $F$. oxysporum. About 50 isolates obtained from 14 of the wilted plants produced conidial chains on KCL media and were tentatively identified as isolates of $F$. fujikuroi or $F$. proliferatum based on BLAST search of their EF1- $\alpha, P H O$, and $B T$ gene sequences against the GenBank whole-genome shotgun contigs and nucleotide collection databases and Fusarium-ID database (http://isolate.fusariumdb.org/guide.php).

Isolates were subjected to VCG analysis. In total, eight VCG were found among $492 F$. oxysporum isolates and seven VCG and one single-member VCG were found among conidial chain-forming $F$. fujikuroi or $F$. proliferatum isolates. Multiple members of each VCG were further tested with nit- $M$ testers of the known VCG in $F$. oxysporum f. sp. vasinfectum (Ortiz et al. 2016). None of the VCG from $F$. fujikuroi or $F$. proliferatum isolates complemented with the testers. The complementation tests identified the eight F. oxysporum VCG as VCG 0111 (race 1), 0112 (race 2), 01117B, 01117C, 01118, and 01119 (race 8), 01120, and 01121. The number of wilted plants analyzed, the number of plants infested by each VCG, and the number of isolates in the identified VCG in each of the seven fields located in the five counties along with cultivar information are given in Table 1.

The genetic variability within each VCG and the genetic relationship among VCG were assessed by DNA sequence analysis of the EF1- $\alpha, P H O$, and $B T$ genes comprising more than $5.6 \mathrm{~kb}$ of genomic sequence for three isolates in each VCG, except VCG 01119 (Fig. 1). The three sequenced isolates were chosen so that they preferably were from different fields or at least from different plants. VCG 01119 occurred only in one plant; thus, only two isolates were analyzed. Sequences within a VCG were all identical. No sequence difference was detected between the VCG 01117B and VCG 011117C (Fig. 1). Phylogenic analysis based on these sequences suggests that VCG $0111,0112,01117 \mathrm{~B}$, and $01117 \mathrm{C}$ are closely related because they formed a clade, and VCG 01119,1120 , and 01121 are closely related, forming another clade. VCG 01118 is the most remotely related VCG and formed an independent clade.

Overall, VCG 01121 infected the highest number of plants (39\%) followed by VCG 01117B (35\%), VCG 01117C (9\%), VCG 01118 (7\%), VCG 01120 (5\%), VCG 0112 (4\%), VCG 0111 (3\%), and VCG 01119 (1\%). Only VCG 01117B and 01121 were found in all fields in the five counties. VCG 0111 was found only in Berrien County, VCG 0112 only in Evans County, VCG 01118 only in Cook and Grady Counties, and VCG 01119 and 01120 only in Grady County.

The distribution of VCG was unique in each county. The two fields within Evans County had very similar VCG distribution, with VCG 01117B predominating (Table 1). The same was true with Tift County fields, with the presence of only VCG 01117B and 01121. Berrien and Cook Counties, especially the former, were characterized by a high population of VCG 01121 . Notable for Grady County was the relatively high population of VCG 01120.

No association of VCG with cultivar susceptibility was apparent (Table 1). DP 1454 NR B2RF cotton with moderate susceptibility (Smith et al. 2015) was planted in Berrien and Grady Counties, yet the two sites have distinctively different VCG distribution. The same can be said about the moderately resistant DP 1050 B2RF (Smith et al. 2015), which was planted in Evans and Cook Counties.

Interactions among VCG. Individual plants infected by multiple VCG were observed at low frequencies (Table 2). Only one plant in the whole collection was attacked by more than two VCG; this plant 
occurred in Berrien County and was attacked by VCG 0111, 01117B, and 01121. Therefore, only observed numbers of individual plants attacked by two VCG were included in Table 2, along with all the expected frequencies calculated using the frequencies of each VCG in a given field available from Table 1, assuming that infection by the second isolate belonging to another VCG was independent with regard to the presence of the first isolate in the plant and the presence of other VCG in the field. An example of the calculation is given in the "Vegetative compatibility analysis" section of Methods and Materials. The relatively large number of plant and isolate samples from across the state provided an opportunity to investigate interactions among VCG. Examination of relationships between the observed and expected numbers of individual plants simultaneously infected by two specific VCG in each field revealed an overall tendency of observed numbers slightly less than expected numbers. The statistical significance of this trend was tested by modeling the data with linear regression using PROC REG in SAS, treating the observed number as the outcome variable regressed against the expected number. Regression gives the following linear function (number of observed) $=-0.15+0.58 \times$ (number of expected) with adjusted $R^{2}$ of 0.55 . Further testing of significant deviation of the intercept and slope from 0 and 1, respectively, indicates that the intercept is not significantly different from $0(P=0.24)$ but the slope is significantly different from $1(P<0.0001)$. Therefore, the lower observed number than the expected number in overall data is statistically significant, as shown by the slope of $0.58<1$.

Examination of a subset of data in Table 2 for the VCG 01117B and 01121 (1B and 12) pair interaction across all seven fields gives the impression that the observed numbers are quite close to the expected numbers. Again, we modeled the subset data to give a linear function: (number of observed) $=-0.39+0.91 \times$ (number of expected) with adjusted $R^{2}$ of 0.64 . This time, both the intercept and slope were not significantly different from $0(P=0.48)$ and 1 $(P=0.75)$, respectively, confirming the impression. The slope of 0.91 is much closer to 1 than that of 0.58 in the whole-data modeling.

Vascular competency. The pathotype determination for the Georgia $F$. oxysporum f. sp. vasinfectum was first conducted by stempuncture assay, which introduced the fungus directly into xylem, to see whether the isolate is competent enough in the vasculature to cause disease. To alleviate complications arising from variations of virulence among isolates within each VCG, mean responses of all the isolates within each VCG were used for the analysis, and the numbers of isolates in each VCG are given in Table 3. A highly virulent vascular-competent pathotype VCG 01117A isolate, ATCC
46644, was used as a positive control with six replicates, and the 50 conidial chain-forming $F$. fujikuroi or $F$. proliferatum isolates as the negative controls. Three weeks after inoculation, none of the negative control plants developed wilt symptoms; the value for percent leaves wilted was only $0.7 \%$. All of the Georgia VCG and the positive controls caused wilt symptoms, with percent leaves wilted value ranging from 27.4 to 54.1. VCG 01118 caused the least leaf symptoms (27.4\% wilted leaves), which was significantly less than that caused by other VCG except VCG 0111.

All VCG, including positive control VCG 01117A, caused significant reduction in fresh leaf weight and fresh shoot weight in ranges of 39.5 to 67.3 and 32.9 to $60.4 \%$, respectively, compared with corresponding weights of the negative control. Several significant differences were detected in mean responses of weights among the treatments by these VCG. Mean shoot height responses were slightly less responsive to $F$. oxysporum $\mathrm{f}$. sp. vasinfectum: all but VCG 0111 caused significant height reduction of 11.0 to $21.8 \%$ compared with the negative control. Significant differences were also detected among VCG in mean height reductions.

Interaction with root-knot nematodes. Representative isolates of Georgia VCG were tested for virulence using the soil-infestation assay with or without root-knot nematodes. Data from selected isolates were used to obtain the means for VCG shown in Table 4. None of the mean response variables (fresh shoot weight, shoot height, percent leaves wilted, and vascular browning) of each VCG were significantly different from that of the control treatment in the absence of root-knot nematodes, except for a decrease in shoot weight for VCG 0111, 01117C, and 01118 and an increase in vascular browning for VCG 01121 (Table 4). The nematode by itself, at 6,000 eggs per plant inoculation, did not cause disease symptoms in the aboveground portion of the plants (Table 4). VCG 0112, 01117B, 01117C, 01120, and 01121 in the presence of nematodes significantly reduced shoot weight and height by 30 to 65 and 22 to $42 \%$, respectively, and significantly increased percentage of leaves wilted and vascular browning by 23 to 48 and 1.2 to 2 , respectively, compared with that in the absence of nematodes. VCG 01118 in the presence of the nematode significantly increased vascular browning index by 0.6 but increases of percentage of leaves wilted and reductions in shoot weight and height were not significant compared with the treatments without nematodes. VCG 0111 in the presence of the nematode also caused small nonsignificant reductions in shoot weight and height and increases of percentage leaves wilted and vascular browning compared with the treatments without nematodes (Table 4).

Table 3. Mean effects of stem-puncture inoculations of Gossypium hirsutum 'Rowden' with different vegetative compatibility groups (VCG) of Fusarium oxysporum f. sp. vasinfectum isolates from Georgia compared with nonpathogenic $F$. fujikuroi or $F$. proliferatum isolates from the same collection and a highly virulent VCG 01117A isolate (ATCC 46644) from California on fresh leaf and fresh shoot weight, shoot height, or percent leaves wilted at 3 weeks after inoculation ${ }^{\mathrm{x}}$

\begin{tabular}{lccccc}
\hline VCG $^{\mathbf{y}}$ & Number of isolates & Leaves wilted $(\boldsymbol{\%})^{\mathbf{z}}$ & Leaf weight $(\mathbf{g})$ & Shoot weight $(\mathbf{g})^{\text {Shoot height }(\mathbf{c m})}$ \\
\hline $0111(4)$ & 13 & $37.0 \mathrm{ab}$ & $13.3(39.5) \mathrm{bc}$ & $21.0(32.9) \mathrm{c}$ & $39.9(6.6) \mathrm{bc}$ \\
$0112(5)$ & 14 & $45.2 \mathrm{a}$ & $12.0(45.5) \mathrm{abc}$ & $18.9(39.6) \mathrm{bc}$ & $38.8(9.1) \mathrm{ab}$ \\
$01117 \mathrm{~A}(1 \mathrm{~A})$ & 1 & $54.1 \mathrm{a}$ & $7.2(67.3) \mathrm{a}$ & $12.4(60.4) \mathrm{a}$ & $33.4(21.8) \mathrm{a}$ \\
$01117 \mathrm{~B}(1 \mathrm{~B})$ & 181 & $41.5 \mathrm{a}$ & $10.5(52.3) \mathrm{ab}$ & $16.8(46.3) \mathrm{ab}$ & $36.9(13.6) \mathrm{ab}$ \\
$01117 \mathrm{C}(1 \mathrm{C})$ & 46 & $46.3 \mathrm{a}$ & $9.6(56.4) \mathrm{a}$ & $16.1(48.6) \mathrm{ab}$ & $38.0(11.0) \mathrm{ab}$ \\
$01118(8)$ & 34 & $27.4 \mathrm{~b}$ & $13.0(40.9) \mathrm{c}$ & $19.9(36.4) \mathrm{c}$ & $39.1(8.4) \mathrm{b}$ \\
$01119(2)$ & 6 & $47.2 \mathrm{a}$ & $11.5(47.7) \mathrm{abc}$ & $18.0(42.5) \mathrm{abc}$ & $39.1(8.4) \mathrm{ab}$ \\
$01120(10)$ & 20 & $38.2 \mathrm{a}$ & $12.5(43.2) \mathrm{bc}$ & $19.3(38.3) \mathrm{bc}$ & $37.9(11.2) \mathrm{ab}$ \\
$01121(12)$ & 178 & $45.1 \mathrm{a}$ & $9.9(55.0) \mathrm{a}$ & $16.1(48.6) \mathrm{ab}$ & $36.2(15.2) \mathrm{a}$ \\
Control & 50 & $0.7 \mathrm{c}$ & $22.0 \mathrm{~d}$ & $31.3 \mathrm{~d}$ & $42.7 \mathrm{c}$ \\
\hline
\end{tabular}

${ }^{x}$ Values are the least squares means of the responses treated by the number of isolates indicated in the second column for each VCG, except for the positive control VCG 01117A (ATCC 46644), which is the least squares mean of six replicates treated by this one isolate. Means were separated at $P=0.05$ using least squares means with the Tukey-Kramer adjustment. Means with the same letter within the column are not significantly different. Percent reduction compared with control was given in the parenthesis.

y International VCG codes are given, followed by the local VCG codes (Insect Control and Cotton Disease Research Unit, USDA-ARS) in parentheses. Race 1 reference isolate ATCC 16421 belongs to VCG 0111, race 2 reference isolate ATCC 16611 to VCG 0112, and race 8 reference isolate NRRL31665 to VCG 01119. A highly pathogenic VCG 01117A isolate (ATCC 46644) from California was used as positive control. Controls consisted of plants inoculated with nonpathogenic isolates of conidial chain-forming Fusarium spp. tentatively identified as $F$. fujikuroi or F. proliferatum.

${ }^{z}$ Percentage of leaves wilted was calculated by dividing the wilted number of leaves with total number of leaves including the leaf scars within a wilted plant multiplied by 100 . 
In the presence of nematodes, all VCG caused significant reductions in shoot weight (34 to 63\%) and height (26 to 44\%) and significant increases in percentage of wilted leaves (24 to $47 \%$ ) and vascular browning index (0.8 to 2.1) compared with water-treated control plants, except that VCG 0111 and 01121 caused nonsignificant $(P=0.05)$ reductions in shoot weight (29 to 36\%), VCG 0111 and 01118 nonsignificant $(P=0.05)$ increases in percentage of wilted leaves ( 8 to $22 \%)$, and VCG 0111 nonsignificant $(P=0.05)$ increases in vascular browning index (0.9) (Table 4). Some significant differences in these responses were detected among VCG treatments.

Variations in virulence of individual isolates within each VCG were assessed by analyzing the same data for fresh shoot weight response variable from Table 4 by conducting analyses separately within each VCG plus the water control. The variations were discernable in each VCG but the overall trend was consistent with the Table 4 data.

\section{Discussion}

Eight VCG (VCG 0111, 0112, 01117B, 01117C, and 01118 to 01121), comprising $492 F$. oxysporum f. sp. vasinfectum isolates, were found in Georgia near the end of the 2014 cotton season. Finding VCG 0111 in Berrien County was a surprise because no other member of this VCG had ever been reported since Armstrong and Armstrong (1958) deposited isolate ATCC 16421 from Clemson, $\mathrm{SC}$ as the race 1 reference isolate at the ATCC. Fernandez et al. (1994) assigned VCG 0111 to this single isolate. Sequencing of the $E F 1-\alpha, P H O$, and $B T$ genes, comprising more than $5.6 \mathrm{~kb}$ of genomic sequence from three isolates of the VCG each from different wilted plants, showed that they had identical sequences, which were the same as those of isolate ATCC 16421 (Ortiz et al. 2016). Isolates of VCG 0111 occurred only in Berrien County, accounting for 13\% of $F$. oxysporum f. sp. vasinfectum-infected plants. These isolates caused disease in the stem-puncture assay but not in the soilinfestation assay in the absence of root-knot nematodes. Therefore, this VCG in Georgia is a vascular-competent pathotype just like isolate ATCC 16421 (Bell et al. 2016; Liu et al. 2011). Measurable but insignificant $(P=0.05)$ changes occurred in the four measured disease response variables in the presence versus absence of nematodes. This indicates that VCG 0111 is a relatively weak vascularcompetent pathotype. This VCG has a unique two-base deletion at position $41 \mathrm{bp}$ of the $E F 1-\alpha$ gene that is not present in any other F. oxysporum f. sp. vasinfectum VCG (Ortiz et al. 2016). Therefore, sequencing around this region provides a quick confirmation of the VCG 0111 identity. We routinely used primer pair EF-1A, 5'-CACCTTAAC GTCGTCGTCATC and EF516R, 5'-AAGAACCCAGGCGTACTTGA for this purpose.

VCG 0112 (race 2), 01117A, 01117B, 01117C, and 01119 (race 8) are the most widely distributed and abundant VCG in the United States (Bell et al. 2016; Ortiz et al. 2016). VCG 01117A was not observed in Georgia and VCG 01119 was found in only one infected plant in Grady County. Stem-puncture assays with Georgia VCG 01119 isolates indicated that they, too, like VCG 01119 isolates from other states, belong to vascular-competent pathotypes. All VCG 01119 isolates that have been sequenced, including the race 8 reference isolate NRRL31665 from China, have identical DNA sequences (Ortiz et al. 2016). VCG 0112 occurred only in Evans County in Georgia, comprising a mere $15 \%$ of wilted plants. VCG $01117 \mathrm{~B}$ occurred in all five counties and was the major or second most prevalent VCG in all but Berrien and Tift (field 1A only) Counties. VCG $01117 \mathrm{C}$ occurred only as a minor component in Evans $(15 \%$ of wilted plants), Berrien (22\%), and Cook (6\%) Counties. VCG 0112, 01117B, and 01117C share the same clade with VCG 0111 (Fig. 1), and Georgia isolates within each of these VCG shared identical DNA sequences which also were identical to sequences of isolates of each of these VCG from other states. Stem-puncture and soilinfestation with Georgia VCG 0112, 01117B, and 01117C confirmed that these VCG are highly pathogenic and belong to the vascularcompetent pathotype, as established previously (Bell et al. 2016). The assays also demonstrated strong interaction with root-knot nematodes causing severe disease compared with soil-infestation with the fungus alone.

VCG 01120 and 01121 share the same clade with VCG 01119 (race 8; Fig. 1). VCG 01120 occurred only in Grady County as the second most prevalent VCG (38\% of the wilted plants). Only two isolates of VCG 01120 and one isolate of VCG 01121 from the neighboring state of Alabama were found in our 1992-1995 collection of more than 1,000 isolates of Fusarium resembling $F$. oxysporum from wilted cotton plants and cotton field soils throughout the midsouth and southeast cotton belt (Bell et al. 2016). The $45 F$. oxysporum isolates from wilted cotton plants collected in the 2010 and 2011 growing seasons from the Fusarium wilt nursery (provided by Dr. Kathy Lawrence, Department of Entomology \& Plant Pathology, Auburn University) included 17 VCG 01120 isolates but no VCG 01121 isolates. Alabama VCG 01120 and 01121 isolates, like the Georgia counterparts in the present

Table 4. Fresh shoot weight, shoot height, percent leaves wilted, and vascular browning index (VBI) of Gossypium hirsutum 'Rowden' grown in soil infested with isolates from different vegetative compatibility groups (VCG) of Fusarium oxysporum f. sp. vasinfectum from Georgia with or without root-knot nematodes $(\mathrm{RKN})\left(\right.$ Meloidogyne incognita) ${ }^{\mathrm{w}}$

\begin{tabular}{|c|c|c|c|c|c|c|c|c|}
\hline \multirow[b]{2}{*}{$\mathrm{VCG}^{\mathrm{z}}$} & \multicolumn{2}{|c|}{ Shoot weight (g) } & \multicolumn{2}{|c|}{ Shoot height (cm) } & \multicolumn{2}{|c|}{ Leaves wilted $(\%)^{\mathrm{x}}$} & \multicolumn{2}{|c|}{ VBIy } \\
\hline & $-\mathbf{R K N}$ & $+\mathrm{RKN}$ & - RNK & $+\mathrm{RKN}$ & $-\mathbf{R K N}$ & $+\mathrm{RKN}$ & $-\mathbf{R K N}$ & $+\mathrm{RKN}$ \\
\hline $0111(4)$ & $7.6 \mathrm{~A} \mathrm{a}$ & 7.4 A abcd & $11.5 \mathrm{~A} \mathrm{a}$ & $11.3 \mathrm{~A} \mathrm{ab}$ & $10.9 \mathrm{~A} \mathrm{a}$ & $27.5 \mathrm{~A} \mathrm{abc}$ & $0.5 \mathrm{~A} \mathrm{ab}$ & $1.2 \mathrm{~A} \mathrm{ab}$ \\
\hline $0112(5)$ & $12.2 \mathrm{~A} \mathrm{bc}$ & $4.3 \mathrm{~B} \mathrm{ab}$ & $15.3 \mathrm{~A} \mathrm{bc}$ & $8.9 \mathrm{~B} \mathrm{ab}$ & $4.4 \mathrm{~A} \mathrm{a}$ & $52.3 \mathrm{~B} \mathrm{~cd}$ & $0.4 \mathrm{~A} \mathrm{ab}$ & $2.4 \mathrm{~B} \mathrm{bc}$ \\
\hline 01117B (1B) & $11.0 \mathrm{~A} \mathrm{bc}$ & $7.7 \mathrm{~B} \mathrm{c}$ & $14.6 \mathrm{~A} \mathrm{bc}$ & $11.4 \mathrm{~B} \mathrm{~b}$ & $12.1 \mathrm{~A} \mathrm{a}$ & $38.9 \mathrm{~B} \mathrm{~cd}$ & $0.4 \mathrm{~A} \mathrm{ab}$ & $2.0 \mathrm{~B} \mathrm{bc}$ \\
\hline $01117 \mathrm{C}(1 \mathrm{C})$ & $9.6 \mathrm{~A} \mathrm{ab}$ & $4.8 \mathrm{~B} \mathrm{a}$ & $12.7 \mathrm{~A} \mathrm{a}$ & $9.0 \mathrm{~B} \mathrm{a}$ & $12.0 \mathrm{~A} \mathrm{a}$ & $52.6 \mathrm{~B} \mathrm{~d}$ & $0.6 \mathrm{~A} \mathrm{ab}$ & $2.3 \mathrm{~B} \mathrm{c}$ \\
\hline $01118(8)$ & $9.0 \mathrm{~A} \mathrm{a}$ & $7.5 \mathrm{~A} \mathrm{bc}$ & $13.1 \mathrm{~A} \mathrm{ab}$ & $11.7 \mathrm{~A} \mathrm{~b}$ & $6.3 \mathrm{~A} \mathrm{a}$ & $14.0 \mathrm{~A} \mathrm{ab}$ & $0.5 \mathrm{~A} \mathrm{ab}$ & $1.1 \mathrm{~B} \mathrm{~b}$ \\
\hline $01120(10)$ & $12.1 \mathrm{~A} \mathrm{c}$ & $6.4 \mathrm{~B} \mathrm{ac}$ & $15.7 \mathrm{~A} \mathrm{~cd}$ & $10.8 \mathrm{~B} \mathrm{ab}$ & $10.9 \mathrm{~A} \mathrm{a}$ & $42.9 \mathrm{~B} \mathrm{~cd}$ & $0.3 \mathrm{~A} \mathrm{ab}$ & $1.6 \mathrm{~B} \mathrm{bc}$ \\
\hline 01121 (12) & $11.8 \mathrm{~A} \mathrm{c}$ & $8.2 \mathrm{~B} \mathrm{~cd}$ & $15.1 \mathrm{~A} \mathrm{bc}$ & $11.4 \mathrm{~B} \mathrm{~b}$ & $7.2 \mathrm{~A} \mathrm{a}$ & 29.9 B bc & $0.5 \mathrm{~A} \mathrm{~b}$ & $1.7 \mathrm{~B} \mathrm{bc}$ \\
\hline Control & $12.7 \mathrm{~A} \mathrm{c}$ & $11.6 \mathrm{Ad}$ & 14.9 A abcd & $15.9 \mathrm{~A} \mathrm{c}$ & $6.9 \mathrm{~A} \mathrm{a}$ & $6.0 \mathrm{~A} \mathrm{a}$ & $0.0 \mathrm{~A} \mathrm{a}$ & $0.3 \mathrm{~A} \mathrm{a}$ \\
\hline
\end{tabular}

${ }^{\mathrm{w}}$ In all, 3 each of the VCG 0111 and VCG 0112 isolates, 13 VCG 01117B isolates, 12 VCG 01117C isolates, 6 VCG 01118 isolates, 5 VCG 01120 isolates, and 7 VCG 01121 isolates were used as $F$. oxysporum $\mathrm{f}$. sp. vasinfectum inoculum. Values are the least squares means of the responses treated by the indicated number of isolates within each VCG, with three replicates for without-RKN $(-\mathrm{RKN})$ and two replicates for with $\mathrm{RKN}(+\mathrm{RKN})$ for each isolate in each of the two trials. Means were separated at $P=0.05$ using least squares means with the Tukey-Kramer adjustment. Means with the same lowercase letter within the column are not significantly different. Means with same uppercase letter within the $-\mathrm{RKN}$ and $+\mathrm{RKN}$ pairs within the row are not significantly different.

x Percentage of leaves wilted was calculated by dividing the wilted number of leaves with total number of leaves including the leaf scars within a wilted plant multiplied by 100 .

y VBI was assigned with the following scale: $0=$ no staining, $1=0$ to $10 \%$ of cross section was stained, $2=10$ to $30 \%$ of area was stained, $3=30$ to $70 \%$ of area stained, $4=70$ to $90 \%$ of area stained, and $5=90$ to $100 \%$ of area was stained or the plant was dead.

${ }^{\mathrm{z}}$ International VCG codes are given followed by the local VCG codes (Insect Control and Cotton Disease Research Unit, USDA-ARS) in the parentheses. Race 1 reference isolate ATCC 16421 belongs to VCG 0111 and race 2 reference isolate ATCC 16611 to VCG 0112. Controls consisted of plants inoculated with water instead of $F$. oxysporum f. sp. vasinfectum inoculum with six replicates for the $-\mathrm{RKN}$ treatments and four replicates for the $+\mathrm{RKN}$ treatments in each of the two trials. 
study, proved to be the vascular-competent pathotype, as assessed by the stem-puncture and soil-infestation assays.

LA110 genotype isolate LA110 (provided by Hung K. Doan, Department of Plant Pathology, University of California, Davis) was compatible with VCG 01121 in our study and had identical sequences with Georgia VCG 01121 isolates when we sequenced it but had one base difference from the BT gene deposited by Holmes et al. (2009) at NCBI. Examination of Holmes's sequence revealed that the primer BT-5 sequence was not trimmed from the gene sequences. Therefore, the single base difference is probably due to the artificial modification by the primer sequence. Note that Holmes's sequences for partial EF1-a, $P H O$, and $B T$ genes totaled $1,550 \mathrm{bp}$ compared with $5.6 \mathrm{~kb}$ of sequences in our study. In 2012 and 2013 U.S. F. oxysporum f. sp. vasinfectum surveys, LA110 (VCG 01121) was found only in 2012 and only in Georgia, comprising 3 of 12 isolates from that state (Cianchetta et al. 2015).

VCG 01118 was phylogenetically the most distantly related group among Georgia VCG, forming an independent clade by itself (Fig. 1). Three isolates of this VCG from Alabama were found in 1992 to 1995 (Bell et al. 2016) and all had DNA sequences identical with the sequences of Georgia VCG 01118. These isolates, like the Georgia VCG 01118, caused disease in the stem-puncture assay but not in the soil-infestation assay in the absence of root-knot nematodes (Bell et al. 2016). Georgia VCG 01118 had a weak interaction with root-knot nematodes, causing significant increase only in vascular browning and small but insignificant $(P=0.05)$ changes in three other disease responses. DNA sequences of the LA127/140 genotype isolates LA127 and LA140 reported by Holmes et al. (2009) were identical to sequences of VCG 01118 after the former's primer sequences were trimmed from the $B T$ gene, as discussed above. Sequences from three genes $(5.6 \mathrm{~kb})$ of LA127 and LA140 also were identical to sequences of VCG 01118 . However, LA127 and LA140 failed to complement VCG 01118, even though they were self-compatible and complemented each other. The relationship between VCG 01118 and the LA127/140 genotype thus needs further elucidation.

The presence of VCG 01121 isolates in all of the seven fields in Georgia and its presence as the major group in three of the five counties suggest a possible link between its presence and the severe Georgia $F$. oxysporum f. sp. vasinfectum outbreaks. Especially noticeable is the fact that, at the epicenter in Berrien County, this VCG occurred in 74\% of the wilted plants. Considering that the five counties are adjacent to 8 of 10 top 2014 cotton-producing counties in Georgia (https:// www.nass.usda.gov/Statistics_by_State/Georgia/index.php), the potential threat by this VCG is a concern. How long this VCG was established in Berrien County is currently unknown and the disparity in VCG distributions among the five counties emphasizes the importance of monitoring the genotype composition with regard to VCG over time and location. Undoubtedly, the genotype composition will depend on the relative competitiveness of the member VCG in the soil microbial community, the host, and the environment. The occurrence of individual plants simultaneously attacked by more than one VCG offered a glimpse of the competitions among VCG. For plants infected by two VCG, some evidence suggests a possible suppression of invasion by a VCG by the presence of another VCG. However, this was not true for all the VCG pairs. In the case of the VCG 01117B and 01121 pair, invasion by one VCG was not influenced by the presence of the other.

In summary, this study demonstrates the importance of categorizing F. oxysporum f. sp. vasinfectum using both VCG tests and analysis of relatively long DNA sequences in conjunction with discriminating pathogenicity assays on large numbers of isolates within each VCG. Fortunately, only the vascular-competent pathotype VCG that require nematodes for severe disease were present in Georgia. Therefore, use of nematode resistance cultivars remains the most viable approach to control the disease in Georgia. Cotton lines highly resistant to rootknot and reniform (Rotylenchulus reniformis) nematodes have been developed (Bell et al. 2015).

\section{Acknowledgments}

We thank Cotton Incorporated for their partial support of this research; R. M. Davis and H. K. Doan, University of California, Davis, for providing fungal isolates with LA genotype type designations; K. S. Lawrence, Auburn University, for providing fungal isolates collected in 2010 and 2011 cotton growing seasons in Alabama; and the ARS Culture Collection (NRRL) for supplying isolates.

\section{Literature Cited}

Armstrong, G. M., and Armstrong, J. K. 1960. American, Egyptian, and Indian cotton-wilt Fusaria: Their pathogenicity and relationship to other wilt Fusaria. Tech. Bull. U.S. Dep. Agric. 1219:1-19.

Armstrong, G. M., and Armstrong, J. K. 1978. A new race (race 6) of the cottonwilt Fusarium from Brazil. Plant Dis. Rep. 62:421-423.

Armstrong, J. K., and Armstrong, G. M. 1958. A race of the cotton-wilt Fusarium causing wilt of Yelredo soybean and flue-cured tobacco. Plant Dis. Rep. 42. 147-151.

Assigbetse, K. B., Fernandez, D., Dubois, M. P., and Geiger, J. P. 1994. Differentiation of Fusarium oxysporum $\mathrm{f}$. sp. vasinfectum races on cotton by random amplified polymorphic DNA (RAPD) analysis. Phytopathology 84:622-626.

Atkinson, G. W. 1892. Some diseases of cotton. Ala. Agric. Exp. Stn. Bull. 41: $1-65$.

Bell, A. A., Liu, J., Ortiz, C. S., Quintana, J., Stipanovic, R. D., and Crutcher, F. K. 2016. Population structure and dynamics among Fusarium oxysporum isolates causing wilt of cotton. Pages 153-158 in: Proc. Beltwide Cotton Conf. S. Boyd and M. Huffman, eds. National Cotton Council of America, Memphis, TN, and New Orleans, LA.

Bell, A. A., Robinson, A. F., Quintana, J., Duke, S. E., Starr, J. L., Stelly, D. M., Zheng, X. T., Prom, S., Saladino, V., Gutierrez, O. A., Stetina, S. R., and Nichols, R. L. 2015. Registration of BARBREN-713 germplasm line of Upland cotton resistant to reniform and root-knot nematodes. J. Plant Regist. 9:89-93.

Bennett, R. S., Scott, T. Z., Lawrence, K. S., and Lawrence, G. W. 2013. Sequence characterization of race 4-like isolates of Fusarium oxysporum from Alabama and Mississippi. J. Cotton Sci. 17:125-130.

Bugbee, W. M., and Sappenfield, W. P. 1972. Greenhouse evaluation of Verticillium, Fusarium, and root knot nematode on cotton. Crop Sci. 12:112-114.

Chen, Q., Ji, X., and Sun, W. 1985. Identification of races of cotton wilt Fusarium in China. Sci. Agric. Sin. 6:1-6.

Cianchetta, A. N., Allen, T. W., Hutmacher, R. B., Kemerait, R. C., Kirkpatrick, T. L., Lawrence, G. W., Lawrence, K. S., Mueller, J. D., Nichols, R. L., Olsen, M. W., Overstreet, C., Woodward, J. E., and Davis, R. M. 2015. Survey of Fusarium oxysporum f. sp. vasinfectum in the United States. J. Cotton Sci. 19:328-336

Collins, G., Whitaker, J., Culpepper, S., Harris, G., Kemerait, R. C., Perry, C., Roberts, P., Shurley, D., and Smith, A. 2013. 2013 Georgia Cotton Production Guide. Page 45 in: UGA Cotton Web Page. Online publication. The University of Georgia Cooperative Extension. www.ugacotton.com

Correll, J. C., Klittich, C. J. R., and Leslie, J. F. 1987. Nitrate non-utilizing mutants of Fusarium oxysporum and their use in vegetative compatibility tests. Phytopathology 77:1640-1646.

Davis, R. D., Moore, N. Y., and Kochman, J. K. 1996. Characterisation of a population of Fusarium oxysporum $\mathrm{f}$. sp. vasinfectum causing wilt of cotton in Australia. Aust. J. Agric. Res. 47:1143-1156.

Davis, R. M., Colyer, P. D., Rothrock, C. S., and Kochman, J. K. 2006. Fusarium wilt of cotton: Population diversity and implication for management. Plant Dis. 90:692-703.

Day, P. R. 1960. Variation in phytopathogenic fungi. Annu. Rev. Microbiol. 14 $1-16$.

Di Pietro, A., Madrid, M. P., Caracuel, Z., Delgado-Jarana, J., and Roncero, M. I. G. 2003. Fusarium oxysporum: Exploring the molecular arsenal of a vascular wilt fungus. Mol. Plant Pathol. 4:315-325.

Ebbels, D. L. 1975. Fusarium wilt of cotton: A review, with special reference to Tanzania. Cotton Grow. Rev. 52:295-339.

Fernandez, D., Assigbetse, K., Dubois, M. P., and Geiger, J. P. 1994. Molecular characterization of races and vegetative compatibility groups in Fusarium oxysporum f. sp. vasinfectum. Appl. Environ. Microbiol. 60:4039-4046.

Fisher, N. L., Marasas, W. F. O., and Toussoun, T. A. 1983. Taxonomic importance of microconidial chains in Fusarium Section Liseola and effects of water potential on their formation. Mycologia 75:693-698.

Garber, R. H., Jorgenson, E. C., Smith, S., and Hyer, A. H. 1979. Interaction of population-levels of Fusarium oxysporum f. sp. vasinfectum and Meloidogyne incognita on cotton. J. Nematol. 11:133-137.

Gordon, T. R., and Martyn, R. D. 1997. The evolutionary biology of Fusarium oxysporum. Annu. Rev. Phytopathol. 35:111-128.

Holmes, E. A., Bennett, R. S., Spurgeon, D. W., Colyer, P. D., and Davis, R. M. 2009. New genotypes of Fusarium oxysporum f. sp. vasinfectum from the Southeastern United States. Plant Dis. 93:1298-1304.

Hussey, R. S., and Barker, K. R. 1973. Comparison of methods of collecting inocula of Meloidogyne spp., including a new technique. Plant Dis. Rep. 57: 1025-1028.

Hutmacher, R. B., Ulloa, M., Wright, S. D., Campbell, B. T., Percy, R., Wallace, T., Myers, G., Bourland, F., Weaver, D., Chee, P., Thaxton, P., Zhang, J. F., Smith, W., Dever, J., Kuraparthy, V., Bowman, D., Jones, D., and Burke, J. 2013. Elite Upland cotton germplasm-pool assessment of Fusarium wilt resistance in California. Agron. J. 105:1635-1644.

Ibrahim, F. M. 1966. A new race of cotton-wilt Fusarium in the Sudan Gezira. Emp. Cotton Grow. Rev. 43:296-299.

Jorgenson, E. C., Hyer, A. H., Garber, R. H., and Smith, S. N. 1978. Influence of soil fumigation on Fusarium-root-knot nematode disease complex of cotton in California. J. Nematol. 10:228-231. 
Kappelman, A. J. 1983. Distribution of races of Fusarium oxysporum f. sp. vasinfectum within the United States. Plant Dis. 67:1229-1231.

Katan, T., and Di Primo, P. 1999. Current status of vegetative compatibility groups in Fusarium oxysporum: Supplement (1999). Phytoparasitica 27:273-277.

Kim, Y., Hutmacher, R. B., and Davis, R. M. 2005. Characterization of California isolates of Fusarium oxysporum f. sp. vasinfectum. Plant Dis. 89:366-372.

Komada, H. 1975. Development of a selective medium for quantitative isolation of Fusarium oxysporum from natural soil. Rev. Plant Prot. Res. 8:114-124.

Leslie, J. F. 1993. Fungal vegetative compatibility. Annu. Rev. Phytopathol. 31:127-150.

Liu, J., Bell, A. A., Wheeler, M. H., Stipanovic, R. D., and Puckhaber, L. S. 2011. Phylogeny and pathogenicity of Fusarium oxysporum isolates from cottonseed imported from Australia into California for dairy cattle feed. Can. J. Microbiol. 57:874-886.

Nelson, P. E., Toussoun, T. A., and Marasas, W. F. O. 1983. Fusarium Species: An Illustrated Manual for Identification. Pennsylvania State University Press, University Park.

Ortiz, C. S., Bell, A. A., Magill, C. W., and Liu, J. 2016. Specific PCR detection of Fusarium oxysporum $\mathrm{f}$. sp. vasinfectum California race 4 based on a unique Tfo1 insertion event in the PHO gene. Plant Dis. 101:34-44.

Puhalla, J. E. 1985. Classification of strains of Fusarium oxysporum on the basis of vegetative compatibility. Can. J. Bot. 63:179-183.

Puhalla, J. E., and Spieth, P. T. 1983. Heterokaryosis in Fusarium moniliforme. Exp. Mycol. 7:328-335.

Saitou, N., and Nei, M. 1987. The neighbor-joining method-A new method for reconstructing phylogenetic trees. Mol. Biol. Evol. 4:406-425.

Skovgaard, K., Nirenberg, H. I., O'Donnell, K., and Rosendahl, S. 2001. Evolution of Fusarium oxysporum f. sp. vasinfectum races inferred from multigene genealogies. Phytopathology 91:1231-1237.
Smith, A. M., Lawrence, K. S., Glass, K. M., and Santen, E. V. 2015. Evaluation of Fusarium wilt resistance in cotton cultivars and identification of pathogenic races of Fusarium oxysporum f. sp. vasinfectum in Alabama. Pages 608-611 in: Proc. Beltwide Cotton Conf. S. Boyd and H. M., eds. National Cotton Council of America, Memphis, TN, and San Antonio, TX.

Smith, C. W., Cantrell, R. G., Moser, H. S., and Oakley, S. R. 1999. History of cultivar development in the United States. Pages 99-171 in: Cotton: Origin, History, Technology, and Production. C. W. Smith and J. T. Cothren, eds. John Wiley \& Sons, New York.

Snyder, W. C., and Hansen, H. N. 1940. The species concept in Fusarium. Am. J. Bot. 27:64-67.

Tamura, K., Dudley, J., Nei, M., and Kumar, S. 2007. MEGA4: Molecular evolutionary genetics analysis (MEGA) software version 4.0. Mol. Biol. Evol. 24:1596-1599.

Thompson, J. D., Higgins, D. G., and Gibson, T. J. 1994. Clustal-W - improving the sensitivity of progressive multiple sequence alignment through sequence weighting, position-specific gap penalties and weight matrix choice. Nucleic Acids Res. 22:4673-4680

Wang, C., and Roberts, P. A. 2006. A Fusarium wilt resistance gene in Gossypium barbadense and its effect on root-knot nematode-wilt disease complex. Phytopathology 96:727-734.

Whitaker, J., Culpepper, S., Harris, G., Kemerait, R. C., Perry, C., Porter, W., Roberts, P., Shurley, D., and Smith, A. 2016. 2016 Georgia Cotton Production Guide. Pages 60-61 in: UGA Cotton Web Page. Online publication. The University of Georgia Cooperative Extension. www.ugacotton.com

Woloshuk, C. P., Seip, E. R., Payne, G. A., and Adkins, C. R. 1989. Genetic transformation system for the aflatoxin-producing fungus Aspergillus flavus. Appl. Environ. Microbiol. 55:86-90. 